\title{
Examination of Why Some Community Pharmacists Do Not Provide 72-Hour Emergency Prescription Drugs to Medicaid Patients When Prior Authorization Is Not Available
}

\author{
Marvin D. Shepherd, PhD
}

\begin{abstract}
BACKGROUND: Existing federal law requires that a 72-hour emergency supply of a prescription drug be dispensed to Medicaid patients when prior authorization (PA) is not available and the medication is needed without delay. The pharmacist's role is to contact prescribers and inform them that PA is needed. If the prescriber cannot be reached, the pharmacist can dispense a 72-hour emergency supply.
\end{abstract}

OBJECTIVES: To determine (a) the reasons why some community pharmacy owners/managers, staff pharmacists, and technicians are not compliant with the law; (b) how often the decision is made; and (c) estimate how often pharmacies do not dispense the 72-hour emergency supply when PA is not available.

METHODOLOGY: A questionnaire was mailed to selected Texas community pharmacies. The instrument was developed by the researcher and reviewed by the Texas Medicaid Vendor Drug Program staff. The University of Texas, Office of Survey Research collected the data in September and October of 2011 by mail and online. The data were forwarded to the researcher for analyses. A total of 788 identified community pharmacies were mailed a packet containing 3 questionnaires to be completed by the pharmacistin-charge, a staff pharmacist, and a pharmacy technician. There were 2 mailings of the questionnaire packet and follow-up telephone calls to nonrespondents.

RESULTS: A total of 653 questionnaires were completed and returned from 288 community pharmacies (36.7\%) out of 788 pharmacies that were mailed the questionnaire packets. A total of 368 (57.5\%) completed questionnaires came from chain store pharmacy respondents and 272 (42.5\%) questionnaires from independent pharmacy respondents. A total of $21.3 \%$ $(n=134)$ of the respondents indicated that they were not aware of the federal and state requirement to dispense a 72-hour emergency supply of a prescription drug to Medicaid patients when prior authorization $(\mathrm{PA})$ is not available. A greater proportion of the chain store respondents (26.6\%) were unaware of the requirement compared with the independent pharmacy respondents (14.3\%). A total of $77.7 \%$ of the respondents estimated that they make the decision of providing or not providing a 72-hour emergency supply of medication 6 or fewer times a month. A total of $14.6 \%$ indicated that they make the decision 6 to 11 times a month, and $7.7 \%$ make the decision more than 11 times a month.

When asked how often respondents had seen a 72-hour emergency prescription not being dispensed for Texas Medicaid recipients when PA was not available, $49.1 \%$ answered "never"; however, $30.0 \%$ indicated once or twice a month, $16.5 \%$ indicated from 1 to 5 times a week, and another $4.5 \%$ indicated more than 5 times a week. The top 2 reasons for not dispensing a 72 hour-emergency drug supply were: "Reluctant to open a new 'unit-of-use' container (especially 30 -day supply bottles)" and "The Rx will most likely be changed with the PA call, so why dispense a 72-hour supply of the originally prescribed drug?" The top categories of 72-hour emergency prescription drug products that respondents would "likely" dispense were antibiotics; inhaler canisters; products for nausea/vomiting, cough, and cold; antiseizure agents; and diabetic treatment products.

CONCLUSIONS: The results show that there are many factors why pharmacists do not provide 72-hour emergency medications when PA is unavailable. The lack of awareness of the federal and state requirements was significantly related to the frequency of 72-hour medications not being dispensed. In addition, other factors inhibiting the process were the pharmacists' inability to reach physicians or the lack of cooperation with physicians, prescriptions for controlled substances, drug-packing limitations, and the financial risk involved with dispensing a 72-hour supply.

J Manag Care Pharm. 2013;19(7):523-33

Copyright $\odot 2013$, Academy of Managed Care Pharmacy. All rights reserved.

\section{What is already known about this subject}

- No information or study could be found that documents the extent to which pharmacists or technicians follow the 72-hour emergency drug mandate, and no information or study could be found that documents the reasons why community pharmacists are reluctant to provide a 72-hour emergency drug supply for Medicaid recipients when prior authorization (PA) is not available.

\section{What this study adds}

- This study is the first that offers an insight into the concerns of pharmacists and technicians about providing a 72-hour emergency drug supply when PA approval was not accessible for Medicaid patients.

- The study found that $21.3 \%(n=134)$ of the respondents were unaware of the requirement to provide a 72-hour drug supply when PA was unavailable. A greater proportion of the independent pharmacy respondents (85.7\%) were aware of the requirement compared with chain store pharmacy respondents (73.4\%). There was no difference in "awareness" when length of time in pharmacy practice was controlled. 


\section{Examination of Why Some Community Pharmacists Do Not Provide 72-Hour Emergency Prescription Drugs to Medicaid Patients When Prior Authorization Is Not Available}

\section{What this study adds (continued)}

- A greater proportion of respondents who were "unaware" of the legal requirement reported seeing 72-hour drug supplies not being dispensed more often than the "aware" group of respondents. The top reasons why pharmacists and technicians do not provide a 72-hour emergency drug supply when PA is not available were: they do not dispense controlled substances, the medications were expensive, they do not provide products when they feel confident the product will be changed during the PA process, product packaging in containers/bottles hinders a 3-day supply being dispensed, prescriptions are from prescribers who work in emergency rooms or are difficult to locate, the medications are heavily abused or are street-popular drugs, and the request is for vitamins.

- The results found that pharmacists are very reluctant to dispense a 72-hour drug supply for prescriptions written by emergency room physicians. Comments written were: emergency room physicians are very difficult to locate, and it may take multiple calls and many days to get a return telephone call if they even return the call. Also, respondents mentioned many prescribers refuse to do PA, and many are not familiar with the PA process.

- These results point to the realization that pharmacists are not the sole source of the problem of lack of adherence with the 72-hour emergency prescription requirement; prescribers are "partners" in the problem and, in fact, may often precipitate the problem.

巨 xisting federal law requires that a 72-hour emergency supply of a prescription drug be dispensed to Medicaid beneficiaries when the medication is needed without delay and prior authorization (PA) is not available. ${ }^{1}$ This law applies to Medicaid programs that are provided by the state or operated by private managed care firms. Not only is this a federal requirement but it is also a requirement of Texas law. In Texas, this rule applies to drugs not listed on the preferred drug list (PDL) and nonpreferred drugs listed on the preferred drug list and any drug that is affected by a clinical or PA edit.

The prescriber must obtain PA before the pharmacist can dispense the product. The role of the pharmacist is to contact prescribers and inform them that PA is needed before the prescription can be dispensed as written, and prescribers need to get the PA approval from the state or the private managed care organization. If the prescriber cannot be reached, the law states: "The 72-hour emergency supply should be dispensed any time a prior authorization is not available and a prescription must be filled, for any medication or medical condition." The wording from the Texas Medicaid Managed Care Handout is as follows:

"The prescriber must contact the client's MCO (managed care organization) or PBM (pharmacy benefit manager) and follow MCO or PBM guidelines and procedures for prior authorization requests."
If the prescribing provider cannot be reached or is unable to request a PA, the pharmacy should submit an emergency 72-hour prescription. The request for an emergency 72-hour prescription claim should not be used for routine and continuous overrides.

A 72-hour emergency prescription will be paid in full to pharmacy providers and does not count toward the 3-prescription limit for adults who have not already received their maximum prescriptions for the month. ${ }^{2}$

PA requests can be done by fax, web, or telephone, and the MCO must notify the prescriber's office of approval or denial within 24 hours. As mentioned, the MCO must provide full payment to the pharmacy provider for the 72-hour emergency prescription product.

Medicaid prescription drug claims data from November 2007 through October 2008 were used by the Texas Medicaid Vendor Drug Program (VDP) to identify high-volume PA pharmacies with no emergency claims and high-volume PA pharmacies with a below-average number of emergency claims. "High-volume" pharmacies were operationally defined as pharmacies that submitted an above-average number of claims requiring $\mathrm{PA}$ for nonpreferred prescription products. The analysis first identified the total number of prescription claims subject to nonpreferred PA and the total number of emergency claims for all pharmacies. The average number of claims for nonpreferred drugs and the average number of emergency claims were calculated. The average values for both parameters were not released to the researcher.

The Texas Medicaid VDP developed educational programs and communications for the identified pharmacies to inform and remind pharmacists and technicians about the 72-hour emergency supply requirement's procedures and policies. Direct mailings and the VDP RxUpdate newsletter were mailed to community pharmacies, which explained the 72-hour emergency prescription requirement. Educational information was also placed on the VDP website. In addition, when VDP Medicaid auditors/inspectors visited community pharmacies, information was passed on to the pharmacists and technicians.

To obtain a deeper understanding of why pharmacies were not compliant with the law, the Texas VDP contacted the University of Texas, Center for Pharmacoeconomic Studies to conduct a study to determine pharmacist and technician perspectives on the 72-hour emergency requirement and to determine why some pharmacies do not provide the 72-hour emergency supply of medications.

Thus, the purpose of this study was to collect information as to the reasons why some Texas community pharmacies were not providing 72-hour emergency prescription drugs to Medicaid beneficiaries. The VDP wanted to know the perceptions of pharmacy owners/managers, staff pharmacists, and pharmacy technicians as to how often 72-hour emergency prescriptions are not being dispensed and to determine their 
perspectives on 72-hour emergency prescriptions. In examining the literature, no study was found documenting how often pharmacies did not dispense 72-hour emergency drug supplies to Medicaid patients, and no articles were found as to the reasons why 72-hour emergency supply were not dispensed. There were many articles and web postings citing the legal requirements of the 72 -hour emergency drug supply. ${ }^{3-9}$ The purpose of this research was to provide insight as to why some pharmacists and technicians do not provide a 72-hour emergency drug supply when PA cannot be attained.

\section{Methods}

The study design was a survey that used a self-administered questionnaire. Questionnaire packets were mailed to community pharmacies identified by the Texas VDP as not being "fully compliant" with the mandate of providing a 72-hour emergency supply of the medication when PA was not available. Each questionnaire packet mailed to the pharmacies contained 3 color-coded questionnaires: 1 questionnaire was to be completed by the pharmacist-in-charge or owner/manager of the pharmacy, 1 questionnaire was designed for a staff pharmacist employee, and 1 questionnaire was for a pharmacy technician employee. The packet also contained a cover letter that was addressed to the pharmacist-in-charge or owner/manager, explaining the purpose of the study and instructions as to how to distribute the questionnaires to employees. Each questionnaire within the packet had a return-address, postage-paid envelope attached.

The questionnaire was developed by the researcher. A draft version of the questionnaire was forwarded to the Texas VDP to solicit their input, suggestions, and comments. VDP personnel provided useful comments and suggestions, and revisions were made to the instrument. It was resubmitted to VDP for approval. A copy of the final questionnaire can be found in Appendix A (available in online article).

The instrument contained 23 closed-ended items and 2 items that asked for years of practice experience and years of employment at their current pharmacy. It also included 2 open-ended items: 1 asked if the type of drug product prescribed influenced their decision to either dispense or not dispense the 72-hour emergency supply, and 1 asked if there were any internal or corporate business practices/rules that impede the pharmacy from dispensing a 72-hour emergency supply. Respondents were asked to estimate the number of times in the last month they had seen when the drug product dispensed for the 72-hour emergency supply for Medicaid recipients was changed to a different product after PA was obtained. In an open-ended question, respondents were asked to give suggestions on how VDP could improve their educational efforts about the 72-hour emergency medication supply program. Each questionnaire had a unique identification number at the top of the instrument that identified the community pharmacy.
This number facilitated the reminder mailings and follow-up telephone calls. The study was approved by the University of Texas Institutional Review Board.

\section{Data Collection}

The University of Texas, Office of Survey Research (OSR) was contracted by the Texas Medicaid VDP to collect the data from the managers/owners, community pharmacists, and technicians. The Texas VDP provided OSR with a list of addresses and telephone numbers for 801 pharmacies that VDP identified as not being fully compliant with the 72-hour emergency prescription law. OSR sent the mailing list to the U.S. Post Office for address verification. Two pharmacy addresses could not be verified so the questionnaire packets were mailed to 799 pharmacies. This sample represented $16.7 \%$ of the community pharmacies in Texas $(n=4,787)$ in 2011. A total of 2,397 questionnaires were contained in the 799 community pharmacy mailings. In addition, respondents could complete the instrument online via a dedicated website developed by OSR. The website address was provided in the cover letter.

Data collection took place in September and October of 2011. First-class postage was used to mail the packets. Reminder letters, along with questionnaires, were sent to nonrespondent pharmacies 3 weeks after the initial mailing. This was followed-up 3 weeks later by a telephone call reminder. If requested, a questionnaire was faxed to the pharmacies.

The data collected were checked for completeness, entered into a computer file by OSR, and forwarded to the researcher for analysis. OSR provided the data in Excel format on November 17, 2011. The data were transposed and analyzed using SPSS version 18 software (SPSS Inc., Chicago, IL). When t-test and chi-square statistical tests were conducted, an alpha level of 0.05 was employed.

\section{Results}

\section{Response Rates}

Of the 799 questionnaire packets, 16 packets (48 questionnaires) were returned to the sender stamped as "not deliverable," "nonacceptance," "incorrect addresses," or "forwarding address expired." Thus, a total of 783 packets, or 2,349 questionnaires, were assumed to have been delivered.

The data set received from OSR had a total of 653 questionnaires from 288 community pharmacies. Appendix B (available in online article) presents a flowchart of the responses. Based on the number of community pharmacies, the response rate was $36.8 \%$ (288/783). Based on the number of questionnaires mailed, the response rate was $27.8 \%$ $(653 / 2,349)$. A total of $20.5 \%(n=134)$ of the questionnaires were returned through the Internet, using the web-based questionnaires, while the remaining $79.5 \%(n=519)$ of the questionnaires were returned via mail or faxed. Of the 288 pharmacies that received questionnaires, a total of 161 


\begin{tabular}{|c|c|c|c|c|}
\hline \multirow[b]{2}{*}{ Position } & \multicolumn{4}{|c|}{ Number of Questionnaires Received } \\
\hline & $\begin{array}{c}\text { All } \\
\text { Pharmacies } \\
\text { (\%) }\end{array}$ & $\begin{array}{c}\text { Chain Store } \\
\text { Pharmacies } \\
(\%)\end{array}$ & $\begin{array}{c}\text { Independent } \\
\text { Pharmacies } \\
\text { (\%) }\end{array}$ & $\begin{array}{c}\text { "Other" } \\
\text { Pharmacies" } \\
\text { (\%) }\end{array}$ \\
\hline Pharmacist-in-charge & $243 \quad(37.2)$ & $148 \quad(40.2)$ & $90 \quad(33.1)$ & $5(38.5)$ \\
\hline Staff pharmacist & $166 \quad(25.4)$ & $103(28.0)$ & $60 \quad(22.1)$ & $3(23.1)$ \\
\hline Pharmacy owner & $24 \quad(3.7)$ & $1 \quad(0.3)$ & $22 \quad(8.1)$ & $1 \quad(7.7)$ \\
\hline $\begin{array}{l}\text { Lead pharmacy } \\
\text { technician }\end{array}$ & $126 \quad(19.3)$ & $65 \quad(17.7)$ & 59 (21.7) & $2(15.4)$ \\
\hline $\begin{array}{l}\text { Staff pharmacy } \\
\text { technician }\end{array}$ & $94 \quad(14.4)$ & 51 (13.9) & $41 \quad(15.1)$ & $2(15.4)$ \\
\hline $\begin{array}{l}\text { Total number of } \\
\text { questionnaires } \\
\text { received }\end{array}$ & $653(100.0)$ & $368(100.1)$ & $272(100.1)$ & $13(100.1)$ \\
\hline
\end{tabular}

(55.9\%) represented chain store pharmacies, 121 (42.0\%) represented independent pharmacies, and $6(2.1 \%)$ were classified as "Other." "Other" pharmacies were outpatient pharmacies in a clinical setting, mail-order pharmacies, and long-term care pharmacies. Based on the number of questionnaires received from each pharmacy, 140 (48.6\%) pharmacies provided 3 responses per pharmacy, 85 (29.5\%) pharmacies provided 2 responses per pharmacy, and 63 (21.9\%) pharmacies provided only 1 response per pharmacy.

The response rate based on pharmacy position was difficult to determine because it was not known if every pharmacy surveyed employed a staff pharmacist or a technician. In fact, the researcher received calls from pharmacies asking what to do since they did not employ a pharmacy technician and/or a staff pharmacist.

With regard to who completed the instrument, a forcedchoice questionnaire item listed 6 levels of positions. Table 1 depicts the responses by pharmacy position, controlling for type of pharmacy. The Texas VDP staff requested this information because they wanted to examine the data by pharmacy position; they wanted to know if there were differences in perceptions by position.

There were a total of 368 (57.5\%) completed questionnaires from chain store pharmacy respondents and 272 (42.5\%) completed questionnaires from independent pharmacy respondents. Pharmacists-in-charge represented the largest component $(37.2 \%)$, followed by staff pharmacists $(25.4 \%)$. Together, these 2 categories represented $62.6 \%$ of the responses. A total of 24 "owners" completed the instrument. When the categories of "owners" are combined with "pharmacist-in-charge" for independent pharmacies, the total is 112 , which represents $41.2 \%$ of the independent pharmacy responses. This is very similar to the $40.2 \%$ of the chain store respondents who

\section{TABLE 2 The Number and Percentage of Respondents Who Were Aware or Unaware of the Law Requiring that a 72-Hour Emergency Prescription Be Dispensed, Controlling for Practice Setting}

\begin{tabular}{|c|c|c|c|}
\hline \multirow{3}{*}{$\frac{\text { Pharmacy Type }}{\text { Chain store pharmacies }}$} & \multicolumn{3}{|c|}{ Number and Percentage of Respondents } \\
\hline & \multirow{2}{*}{$\begin{array}{c}\text { All } \\
\text { Respondents } \\
\text { N (\%) } \\
357(100.0)\end{array}$} & $\begin{array}{c}\text { Aware } \\
\text { n (\%) }\end{array}$ & $\begin{array}{c}\text { Unaware } \\
\text { n (\%) }\end{array}$ \\
\hline & & $262 \quad(73.4)$ & $95 \quad(26.6)$ \\
\hline Independent pharmacies & $272(100.0)$ & $(85.7)$ & $(14.3)$ \\
\hline All pharmacies & $629(100.0)$ & $495 \quad(78.7)$ & $134 \quad(21.3)$ \\
\hline \multicolumn{4}{|c|}{$\begin{array}{l}\text { a6 respondents did not answer this question. } \\
b \text { There was a statistically significant difference in the proportion of respondents } \\
\text { who are aware of the law requiring a 72-hour emergency prescription, according to } \\
\text { practice setting }\left(\chi^{2}=13.869 ; P=0.001\right) \text {. }\end{array}$} \\
\hline
\end{tabular}

responded as "pharmacist-in-charge." Pharmacy technicians represented $33.7 \%(n=220)$ of all responses. Pharmacy technicians represented $31.6 \%$ of the chain store pharmacy responses and $36.8 \%$ of the independent pharmacy responses

Respondents who answered "owner" $(n=24)$ were consolidated with those who indicated that they were the "pharmacist-in-charge" ( $n=243)$, resulting in 267 responses. Both the lead technician positions and staff-level technicians were consolidated to form 1 group called "technicians" $(n=220)$. The staff pharmacist-level position remained the same, with 166 respondents. Since there were only 13 respondents who indicated "Other" for practice setting, this group of respondents was excluded for most analyses.

\section{Awareness of the 72-Hour Emergency Prescription Rules}

Respondents were asked: "Are you aware that federal and Texas law requires that a 72-hour emergency supply of a prescribed drug be provided to Medicaid patients when prior authorization is not available?" Table 2 depicts the results, controlling for practice setting. A total of $78.7 \%$ of the respondents $(n=495)$ were aware that federal and Texas law required the dispensing of a 72-hour emergency supply. However, $21.3 \%$ of the respondents $(n=134)$ were not aware of the requirement. A greater proportion of the independent pharmacy respondents (85.7\%) were aware of the requirement compared with chain store pharmacy respondents (73.4\%), and this was statistically significant, using a chi-square Fisher exact test $\left(\chi^{2}=13.86 ; P=0.001\right)$.

Appendix $C$ (available in online article) presents the results about "awareness," controlling for practice setting and pharmacy position. A total of $80.5 \%$ of the "pharmacists-in-charge" from independent community pharmacies were aware of the requirement compared with $75.5 \%$ of the chain store pharmacies "pharmacists-in-charge." However, this difference was not statistically significant $\left(\chi^{2}=3.418\right.$; 


\section{Examination of Why Some Community Pharmacists Do Not Provide 72-Hour Emergency Prescription Drugs to Medicaid Patients When Prior Authorization Is Not Available}

\begin{tabular}{|c|c|c|c|c|}
\hline \multirow[b]{3}{*}{ Frequency } & \multicolumn{4}{|c|}{$\begin{array}{l}\text { How Often Respondents Made } \\
\text { Decisions Regarding 72-Hour } \\
\text { Emergency Prescriptions for Medicaid } \\
\text { Recipients, by Position Level }\end{array}$} \\
\hline & \multicolumn{4}{|c|}{ Number and Percentage of Respondents } \\
\hline & $\begin{array}{c}\text { All } \\
\text { Respondents } \\
\text { N (\%) }\end{array}$ & $\begin{array}{c}\text { Pharmacists- } \\
\text { in-Charge } \\
\mathrm{n}(\%)\end{array}$ & $\begin{array}{c}\text { Staff } \\
\text { Pharmacists } \\
\text { n (\%) }\end{array}$ & $\begin{array}{c}\text { Technicians } \\
\text { n (\%) }\end{array}$ \\
\hline $\begin{array}{l}\text { Fewer than } 6 \text { times } \\
\text { last month }\end{array}$ & $504 \quad(77.7)$ & $198 \quad(74.7)$ & 135 (81.8) & $171 \quad(78.1)$ \\
\hline $\begin{array}{l}6 \text { to } 10 \text { times } \\
\text { last month }\end{array}$ & $95 \quad(14.6)$ & $37(14.0)$ & $23(13.9)$ & $35(16.0)$ \\
\hline $\begin{array}{l}11 \text { to } 20 \text { times } \\
\text { last month }\end{array}$ & $32 \quad(4.9)$ & $18 \quad(6.8)$ & $(3.0)$ & $(4.1)$ \\
\hline $\begin{array}{l}\text { More than } 20 \text { times } \\
\text { last month }\end{array}$ & $(2.8)$ & $(4.5)$ & $(1.2)$ & $4 \quad(1.8)$ \\
\hline Totala,b & $649(100.0)$ & $265(100.0)$ & $165(100.0)$ & $219(100.0)$ \\
\hline \multicolumn{5}{|c|}{$\begin{array}{l}\text { a4 respondents did not answer this question: } 2 \text { pharmacists-in-charge, } 1 \text { staff phar- } \\
\text { macist, and } 1 \text { technician. } \\
\text { bThere was no statistically significant difference among the different positions in } \\
\text { how often respondents made decisions regarding } 72 \text {-hour emergency prescriptions } \\
\left(\chi^{2}=9.547 ; P=0.145\right) \text {. }\end{array}$} \\
\hline
\end{tabular}

$P=0.065$ ). For staff pharmacists, there was a statistically significant difference between the settings. A total of $87.9 \%$ of the independent pharmacy staff pharmacists were aware of the requirement compared with $66.0 \%$ of the staff pharmacists from chain store pharmacies $\left(\chi^{2}=9.188 ; P=0.002\right)$. In other words, close to one third of the chain store staff pharmacists were not aware of the regulatory requirement. For technicians, a total of $14.1 \%(n=14)$ of the independent pharmacy technicians were not aware of the rule compared with $22.9 \%(n=25)$ of the chain store technicians. This result for technicians was not statistically significant $\left(\chi^{2}=2.634 ; P=0.105\right)$.

Appendix D (available in online article) depicts the relationship of length of time in pharmacy practice and "awareness." The results show that "awareness" of the regulation did not change, controlling for the length of pharmacy practice experience. Approximately 20\% of the respondents in each of the length of time practice categories were unaware of the law.

\section{Frequency of Decisions for Dispensing a 72-Hour Emergency Prescriptions}

Table 3 shows how often pharmacy employees make a decision about dispensing a 72-hour emergency drug supply. The wording of the item was: "In the last month, please estimate how often you made the decision about providing a 72-hour emergency prescription for Medicaid recipients. This closed-ended question had 4 answer choices: (1) less than 6 times last month, (2) 6 to 10 times last month, (3) 11 to 20 times last month, and (4) more than 20 times last month. A total of $79.0 \%$ of the chain store respondents and $76.9 \%$ of the independent pharmacy respondents indicated that the decision to provide 72 -hour
TABLE 4 Frequency that Respondents Witnessed 72-Hour Emergency Prescriptions Not Being Dispensed in the Last 30 Days, Controlling for Position Level

\begin{tabular}{l|rr|rr|rr|rr}
\hline \multirow{2}{*}{ Frequency } & \multicolumn{5}{|c|}{ Number and Percentage of Respondents } \\
\cline { 2 - 8 } & $\begin{array}{c}\text { All } \\
\text { Respondents } \\
\text { N (\%) }\end{array}$ & $\begin{array}{c}\text { Pharmacists- } \\
\text { in-Charge } \\
\text { n (\%) }\end{array}$ & $\begin{array}{c}\text { Staff } \\
\text { Pharmacists } \\
\text { n (\%) }\end{array}$ & $\begin{array}{c}\text { Technicians } \\
\text { n (\%) }\end{array}$ \\
\hline Never & 317 & $(49.1)$ & 124 & $(46.6)$ & 85 & $(52.5)$ & 108 & $(49.5)$ \\
\hline $\begin{array}{l}\text { Once or twice } \\
\text { a month }\end{array}$ & 194 & $(30.0)$ & 75 & $(28.2)$ & 49 & $(30.2)$ & 70 & $(32.1)$ \\
\hline Once a week & 52 & $(8.0)$ & 25 & $(9.4)$ & 9 & $(5.6)$ & 18 & $(8.3)$ \\
\hline 2-5 times a week & 55 & $(8.5)$ & 27 & $(10.2)$ & 11 & $(6.8)$ & 17 & $(7.8)$ \\
\hline $\begin{array}{l}\text { Greater than } \\
\text { 5 times a week }\end{array}$ & 28 & $(4.3)$ & 15 & $(5.6)$ & 8 & $(4.9)$ & 5 & $(2.3)$ \\
\hline Totala,b & $646(100.0)$ & $266(100.0)$ & $162(100.0)$ & $218(100.0)$ \\
\hline
\end{tabular}

a 7 respondents did not answer this question.

${ }^{b}$ There was no statistically significant difference among the different positions in how often respondents witnessed 72-hour emergency prescriptions not being dispensed $\left(\chi^{2}=8.006 ; P=0.433\right)$

emergency prescriptions was made less than 6 times in the last month. No statistically significant difference was found when controlling for practice setting $\left(\chi^{2}=5.574 ; P=0.134\right)$.

\section{How Often Have You Seen the 72-Hour Emergency Prescription Not Being Used?}

Respondents were asked: "At your pharmacy, in the last 30 days, please estimate how often you have seen the 72-hour emergency prescription NOT being used for Texas Medicaid recipients when prior authorization was not available." Table 4 depicts the results controlling for practice position. Of all the respondents, about half $(49.5 \%)$ reported "never" in the last 30 days and 30.0\% ( $n=194)$ reported "once or twice" in the last 30 days. Eight percent ( $\mathrm{n}=52)$ indicated "once a week" and 8.5\% ( $\mathrm{n}=55)$ respondents reported " 2 to 5 times a week." The remaining $4.3 \%(n=28)$ respondents reported " 5 or more times a week." There was no statistically significant difference when controlling for pharmacy position.

\section{Does Type of Drug Influence the Decision?}

Respondents were asked: "In your opinion, does the type of drug influence the decision on whether or not a 72-hour emergency supply will be dispensed?" A total of $52.5 \%(\mathrm{n}=340)$ of the respondents indicated yes and $47.5 \%(n=308)$ indicated no.

If the respondent answered yes, respondents were asked in an open-ended question to give examples of drug products that would influence their decision as to whether or not a 72-hour emergency supply would be dispensed. A total of 322 responses were submitted: 135 responses from pharmacistsin-charge, 84 responses from staff pharmacists, and 103 responses from pharmacy technicians.

Analyzing the open-ended item was problematic because 


\section{Examination of Why Some Community Pharmacists Do Not Provide 72-Hour Emergency Prescription Drugs to Medicaid Patients When Prior Authorization Is Not Available}

many responses were cryptic in nature to the point that many were incomprehensible. Also, in some cases, it was difficult to determine if the respondent would or would not dispense the product mentioned. In addition, some respondents wrote multiple comments or gave many examples. Despite these shortcomings, the understandable responses provided a valuable insight.

The open-ended responses were categorized into topic areas based on the frequency of the response written. A total of 15 topic areas were identified. Responses that were incomprehensible or infrequent were placed in the "Other" category.

When respondents wrote more than one product or one response, each answer was broken down into multiple categories. Thus, there were a total of 425 different answers from the 322 respondents. Appendix E (available in online article) depicts the top categories and frequencies in decreasing order, controlling for pharmacy position.

When the "Other" category is excluded, the top 5 categories received $59.0 \%$ of the "mentions." The top category, "controlled substances," received 92 mentions (21.6\%), and the distribution was fairly consistent across pharmacy practice positions. Most of the controlled substance mentions concerned either the regulatory issues or the abuse/misuse potential. The following are examples of the comments:

"CII (Schedule II Controlled Substances) medications. This process also creates a billing problem for future fills. Dispensing less than prescribed gives a billing error upon refill and requires multiple steps to correct." (pharmacistin-charge)

"CII meds. Once we fill 3-day supply for patient, the remaining balance of Rx is void and patient will need to get a new hardcopy." (pharmacy technician)

"Controlled substances make us stop and evaluate the patient, drug and usage." (pharmacist-in-charge)

"CII scripts. Pharmacists don't like partials." (pharmacistin-charge)

These results show that pharmacists and technicians do not like or are hesitant to dispense 72-day emergency supplies for controlled substances.

The second most frequent category of mention was antibiotic/anti-infective products. There were 46 responses in this category, with many respondents just writing the word "antibiotics" or a specific product name without an explanation. Some respondents wrote that they would fill a 72 -hour quantity for an antibiotic whereas some wrote they would not because the prescription may be changed after the PA call.

The category "packaging presents difficulty" received the third most frequent number of "mentions." This category relates to how the pharmaceutical product is packaged or bottled. For some products, it is impossible to open the container to dispense a 72-hour supply (i.e., insulin vials, inhalers, eye/ear drops). Another example is when manufacturers use unit-of-use packaging, where the product packages/containers have a fixed number of days of therapy such as blister packaging or other types of fixed-day vial/bottle/container. Liquid products, creams, ointments, and lotions also have limitations because it is extremely difficult to remove just a 72-hour supply. Examples of comments written were:

"If the drug package only comes in a certain quantity ... like 30 or 90 pills or tablets ... we do not break the package. Also ... how are you supposed to give a 72-hour supply of an inhaler or nebulizer solution?" (pharmacist-in-charge)

"Medications that cannot be broken from original box/container; eye drops, ear drops." (pharmacist-in-charge)

"Sometimes if a bottle is sealed, it's difficult to dispense a 3-day supply. The pharmacy will be left with a partial bottle in stock, and if the patient doesn't return, the pharmacy is stuck with inventory." (pharmacist-in-charge)

"Drugs that come prepackaged that would require you to break the package. Then when the doctor is available and changes the medication (which is what usually happens), we are left with the remainder of the package to sit on our shelf." (pharmacy technician)

"Depends on the packaging. Most pharmacists do not feel comfortable breaking a full box for just 3 days. The physician will not call for a PA, and the product stays there to expire."

The category that received the fourth most frequent mentions was "inhalers." It received 38 responses (8.9\%). Respondents either wrote "inhalers" or wrote a specific product name. Respondents indicated that they will dispense this product in an emergency situation.

The fifth-ranked category of comments was titled "expensive." If the respondent viewed the drug product as being costly, they were less inclined to dispense a 72-hour supply of the product. The thinking was that the product would not be approved for PA so why dispense a 72-hour supply of an expensive medication when a generic or less costly product will most likely be prescribed. Examples of types of products that they would not be inclined to dispense are:

"A very expensive narcotic or a very expensive medication that can be easily substituted with another lesser expensive medication."

"High-dollar medications and controlled substances."

"Expensive antibiotics that are reconstituted and then are changed by prescriber to another antibiotic that does not require prior authorization."

"High-price items and package-sized ones are a waste of money knowing that the prescription will be changed." 
TABLE 5 The Distributions and Mean Significance/Importance Ratings on Factors for Not Dispensing 72-Hour Emergency Prescriptions for Respondents

\begin{tabular}{|c|c|c|c|c|c|c|}
\hline \multirow[b]{2}{*}{ Reasons/Factors for Not Dispensing 72-Hour Emergency Prescriptions } & \multicolumn{6}{|c|}{ Rating of Significance/Importance } \\
\hline & $\begin{array}{l}\text { Very High } \\
\text { n (\%) }\end{array}$ & $\begin{array}{l}\text { Moderate } \\
\text { n (\%) }\end{array}$ & $\begin{array}{l}\text { Low } \\
\text { n }(\%)\end{array}$ & $\begin{array}{l}\text { Very Little } \\
\text { n (\%) }\end{array}$ & $\begin{array}{l}\text { None } \\
\text { n (\%) }\end{array}$ & $\begin{array}{l}\text { Mean } \\
\text { Ratinga } \\
\quad(n)\end{array}$ \\
\hline 1. The pharmacist felt the prescribed drug product was not essential ${ }^{b}$ & $104(16.5)$ & $133(21.1)$ & $121(19.2)$ & $71(11.3)$ & $202(32.0)$ & $3.21 \quad(631)$ \\
\hline $\begin{array}{l}\text { 2. The Rx will most likely be changed with the prior authorization call, so } \\
\text { why dispense a } 72 \text {-hour supply of the originally prescribed drugb }\end{array}$ & $143(22.6)$ & $136(21.5)$ & $79(12.5)$ & $98(15.5)$ & $177(28.0)$ & $3.05(633)$ \\
\hline $\begin{array}{l}\text { 3. The pharmacist was reluctant to open a new "unit-of-use" container } \\
\text { (especially } 30 \text {-day supply bottles) }\end{array}$ & $189(30.0)$ & $110(17.4)$ & $82(13.0)$ & $67(10.6)$ & $183(29.0)$ & $2.91(631)$ \\
\hline $\begin{array}{l}\text { 4. Pharmacists or technicians do not fully understand the legal or } \\
\text { processing procedures of a 72-hour emergency supply claim }\end{array}$ & $71(11.3)$ & $105(16.7)$ & $114(18.2)$ & $103(16.4)$ & $235(37.4)$ & $3.52(628)$ \\
\hline 5. Dispensing a 72-hour emergency supply takes too much time ${ }^{b}$ & $15 \quad(2.4)$ & $29 \quad(4.6)$ & $53(8.1)$ & $97(14.9)$ & $433(69.1)$ & $4.44(627)$ \\
\hline 6. The patient decided to wait to have the prescription filled at a later timeb & $127(20.3)$ & $133(21.3)$ & $119(19.0)$ & $76(12.2)$ & $170(27.2)$ & $3.05(625)$ \\
\hline $\begin{array}{l}\text { 7. Dispensing a } 72 \text {-hour emergency supply is not encouraged by pharmacy } \\
\text { or corporate management }{ }^{b}\end{array}$ & $26 \quad(4.1)$ & $34(5.4)$ & $64(10.2)$ & $65(10.4)$ & $438(69.9)$ & $4.36(627)$ \\
\hline $\begin{array}{l}\text { 8. Texas Medicaid prior authorization processes and 72-hour emergency } \\
\text { supply procedures are confusing when compared with other third-party } \\
\text { pay plans }\end{array}$ & $56 \quad(8.9)$ & $65(10.4)$ & $91(14.5)$ & $102(16.2)$ & $314(50.0)$ & $3.88(628)$ \\
\hline Otherc & $44(44.0)$ & $8 \quad(8.0)$ & $11(11.0)$ & $3(3.0)$ & $34(34.0)$ & $2.75(100)$ \\
\hline
\end{tabular}

There were responses that made it difficult to determine if the product(s) mentioned were "likely" or "unlikely" to be dispensed as a 72-hour emergency prescription. The following categories/comments were interpreted by the researcher as being "likely" candidates for the dispensing of a 72-hour emergency supply:

- antibiotic products

- inhalers

- medications for nausea and vomiting

- cough and cold medications

- diabetes treatment products

- eye drops or ear drops

- antiseizure medications

- emergency or urgent care use products

Product categories or comments that were interpreted as being "unlikely" candidates for dispensing of a 72-hour emergency supply were:

- controlled substances

- expensive medications

- product packaging in containers/bottles that make it difficult to dispense a 3-day supply

- prescriptions from prescribers who work in emergency rooms or prescribers who are difficult to locate

- heavily abused medications or street popular drugs

- vitamins

- over-the-counter medications

\section{Reasons for Not Dispensing 72-Hour Emergency Prescriptions}

Respondents were asked: "Please indicate the significance/importance of each of the possible reasons/factors as to why 72-hour emergency prescriptions are not being dispensed to eligible Medicaid beneficiaries in your pharmacy?" We used a 5-point rating scale:

1. Very high significance/very high importance factor

2. Moderate significance/moderate importance factor

3. Low significance/low importance factor

4. Very little significance/very little importance factor

5. Not significant/not an important factor

Thus, the lower the score value, the higher the significance/ importance rating. Table 5 lists the reasons/factors and the results (the Table 5 Appendix, available in online article, lists reasons/factors in the "Other category).

The factor that had the lowest mean score and thus the highest significance/importance rating was "Reluctant to open a new "unit-of-use" container (especially 30-day supply bottle). Two reasons had the same mean scores for the second lowest score and these were: "The pharmacist believes the prescription will most likely be changed with the prior authorization call, so why dispense a 72-hour supply of the originally prescribed drug" and "The patient decided to wait to have the prescription filled at a later time." The 2 reasons with the highest mean score and thus the lowest score on the importance rating were: "Dispensing a 72-hour emergency supply takes too much time" and "Dispensing a 72-hour emergency supply is not encouraged by pharmacy or corporate 


\section{Examination of Why Some Community Pharmacists Do Not Provide 72-Hour Emergency Prescription Drugs to Medicaid Patients When Prior Authorization Is Not Available}

management." There were no statistically significant differences for each of the reasons when controlling for pharmacy position.

\section{Extent of Corporate or Internal Business Practices or Rules}

Respondents were asked, "Are there any pharmacy internal or corporate business practices or rules used that may impede your pharmacy from dispensing 72-hour emergency prescriptions for Medicaid recipients?" A total of $97.5 \%(\mathrm{n}=632)$ indicated no. Only 16 respondents (12 chain employees and 4 independent employees) indicated yes. Those who answered yes were asked to explain their response, and the following comments were made:

"The pharmacy won't be reimbursed for products dispensed that the doctor later won't authorize, and we end up with a loss for the item. The pharmacy has to order products that later won't be covered and we cannot return the products."

"It is our policy to avoid dispensing partial prescriptions on controlled substances or narcotics. Again, these are examined case by case."

"Emergency prescriptions are not dispensed if an ER doctor has written the script. Most ER doctors do not do PA."

"No company wants to lose money. We hesitate to waste a unit-of-use package when we won't be reimbursed if prescription is changed."

"Doctors take too long, sometimes a week or longer to get back with the OK."

"When you call the doctor for a prior authorization, they take at least 4 business days to respond and $99 \%$ of the time the doctor changes the product."

"Corporate is concerned about the cost of inventory and if, for example, a patient needs Xopenex nebules (or prepackaged meds), then we cannot get rid of the rest and we are stuck with a partial quantity of a very expensive medication."

"Controlled substances when prescribing physicians' numbers are not provided and cannot be verified."

"If entered for a 72-hour supply, then Rx has to be entered a second time for info to be faxed to Dr."

"We want to make sure we are reimbursed for all meds."

"The medication is out-of-stock."

"If it is a brand name, we always encourage generic."

"I have heard other pharmacists don't always want to dispense a high-dollar medication because it might not get paid for by Texas Medicaid at a later date."

"Both; if it's a multi-use vial that will last beyond the 72 hrs.- but can't be broken-then we are falsely stating a 3 -day supply on something that lasts up to 30 days or longer, for example."
"Breathing treatments and anti-emetics are allowed. Cough suppressants are usually changed to something else as are prenatal vitamins."

One common theme from the above-listed reasons was the cost risk for the pharmacy. One cost risk is the threat of not being reimbursed for the product, and another cost risk is being left with a partial supply of an expensive drug in a unit-of-use. The second expressed theme was that prescribers are difficult to reach, do not return calls, don't do PA, or, in general, do not have a good understanding of the PA process.

\section{Product Changes After PA Call}

An open-ended question was asked: "Please estimate the number of times in the last month you have seen when the drug product dispensed for the 72-hour emergency supply for Medicaid recipients was changed to a different product after prior authorization was obtained." The results are presented in Appendix F (available in online article), controlling for pharmacy type and position level. A total of 75 respondents failed to answer this question.

Overall, the average number of times in the last month that the prescription was changed after PA was 3.04 times, and the average for chain store employees was slightly higher than respondents from independent pharmacies. However, there was no statistically significant difference between chain store and independent employees. When looking at the results, controlling for pharmacy position, pharmacist-in-charge had the highest mean number of times (3.55), followed by staff pharmacist (3.20) and technicians (2.31). Using a 1-way analysis of variance, there no statistically significant difference between the means, controlling for position $(F=1.802 ; P=0.166)$.

\section{Discussion}

The intent of the 72-hour emergency medication law was to provide access to prescription medication(s) during those times when the decision for PA cannot be obtained. The Texas VDP determined that when the decision of PA could not be obtained, the 72-hour emergency drug supply was not always provided and VDP wanted to know why. This study found that more than $16 \%$ of the respondents indicated that not providing the 72-hour emergency drug supply occurs 1 to 5 times a week, and another 30\% indicated that it happens once or twice a month. This is in direct conflict with the intent of the law.

One possible explanation for the poor compliance with the law was that $21.3 \%$ of the respondents were unaware of the state and federal requirements. A total of $26.6 \%$ of the chain store pharmacy employees were unaware of the requirements compared with $14.3 \%$ of the independent pharmacy employees. More startling was that a total of $34.0 \%$ of the chain store staff pharmacists were unaware of the law's requirements compared with $12.1 \%$ of the independent staff pharmacists. A similar pattern held for technicians. Table 6 shows a statistically 


\section{Examination of Why Some Community Pharmacists Do Not Provide 72-Hour Emergency Prescription Drugs to Medicaid Patients When Prior Authorization Is Not Available}

\begin{tabular}{|c|c|c|c|}
\hline $\begin{array}{l}\text { The N } \\
\text { Respc } \\
72-\mathrm{Hc} \\
\text { Not B } \\
30 \text { D } \\
\text { of the } \\
\text { Chair }\end{array}$ & \multicolumn{3}{|c|}{$\begin{array}{l}\text { The Number and Proportion of } \\
\text { Respondents Who Witnessed } \\
\text { 72-Hour Emergency Prescriptions } \\
\text { Not Being Dispensed in the Last } \\
30 \text { Days, Controlling for "Awareness" } \\
\text { of the Law for Independent and } \\
\text { Chain Store Respondents }\end{array}$} \\
\hline \multirow[b]{2}{*}{ Number of Times } & \multicolumn{3}{|c|}{ "Awareness" } \\
\hline & $\begin{array}{c}\text { All } \\
\text { Respondents } \\
\text { N (\%) }\end{array}$ & $\begin{array}{c}\text { Yes } \\
\text { n (\%) }\end{array}$ & $\begin{array}{c}\text { No } \\
\text { n (\%) }\end{array}$ \\
\hline Never & $\begin{array}{ll}310 \quad(49.3) \\
\end{array}$ & $261 \quad(52.7)$ & $49 \quad(36.6)$ \\
\hline Once or twice a month & $190(30.25)$ & $154 \quad(31.1)$ & $36 \quad(26.9)$ \\
\hline Once a week & $\begin{array}{ll}50 & (7.9) \\
\end{array}$ & $38 \quad(7.7)$ & $12 \quad(9.0)$ \\
\hline 2 to 5 times a week & $(8.3)$ & $(6.5)$ & $20 \quad(14.9)$ \\
\hline Greater than 5 times a week & $27 \quad(4.3)$ & $10 \quad(2.0)$ & $17 \quad(12.7)$ \\
\hline Totala & $629(100.0)$ & $495(100.0)$ & $134(100.1)$ \\
\hline
\end{tabular}

significant relationship between "awareness" of the law and the number of times the respondents witnessed 72-hour emergency drug supplies not being dispensed $\left(\chi^{2}=45.05 ; \mathrm{df}=4 ; P=0.001\right)$. A greater proportion of the "unaware" respondents reported seeing 72-hour drug supplies not being dispensed more often than the "aware" group of respondents. For example, 12.7\% $(\mathrm{n}=17)$ of the "unaware" respondents reported seeing 72-hour supplies not be dispensed 5 or more times a week versus $2.0 \%$ $(n=10)$ of the "aware" respondents, and $14.9 \%(n=20)$ of the "unaware" respondents had observed 72-hour emergency prescriptions not be dispensed 2 to 5 times a week compared with $6.5 \%(\mathrm{n}=32)$ of the "aware" respondents. Although a greater proportion of the "unaware" respondents reported observing the 72-hour prescriptions not being dispensed, close to a third (31.1\%) of the "aware" respondents reported seeing the occurrence once or twice a month.

These results were found after the education programs about the law were provided by the Texas VDP to pharmacists and technicians. VDP mailed educational materials to pharmacies, and educational information was placed in the VDP RxUpdate newsletter. In addition, educational material was placed on the VDP website. Finally, when VDP inspectors/auditors visited community pharmacies, additional educational materials were provided. An "awareness" assessment was not made prior to these education programs so the impact of the educational programming is unknown, but based on this study's results, it appears that additional educational programming is needed.

The results also suggest that education programs need to be provided to both independent and chain store pharmacy practice environments, with a major effort made for chain drugstore employees. One out of every 3 chain store staff pharmacists was unaware of the 72-hour emergency drug requirement. In the researcher's opinion, this educational responsibility does not solely lie upon the State of Texas. The Texas Medicaid program was moved over to the managed care arena on March 1 , 2012, so the educational responsibilities are shared with managed care firms, insurance firms, VDP, corporate pharmacy management, and pharmacy associations. This research also found a variety of reasons why respondents are not always compliant in providing 72-hour emergency medications when PA process is not accessible. The following list provides a brief description of the various reasons:

1. Some drug packaging or drug containers make it difficult to dispense a 72-hour supply. It is impractical to dispense a 72-hour supply of insulin or an inhaler. In addition, pharmacists are reluctant to break open a "unit-of-use" package such as blister packs or a 30-day supply container to dispense a 72-hour drug supply. If the PA is not obtained, the pharmacy will most likely be stuck with a bottle containing 27 days of product that cannot be returned to the wholesaler and most likely will not be sold. Thus a pharmacy will suffer financial loss.

2. Many respondents mentioned that they do not dispense a 72-hour supply of a controlled substance. This is not only associated with abuse and diversion potential; if a 72-hour supply of a controlled substance is dispensed, the prescription is categorized as "filled," and the patient will need to get a new prescription in order to obtain the remaining medication.

3. There was a threat that the prescription will be changed to another product, probably a less expensive product, after contact is made with the prescriber for the PA. Thus, the utility of dispensing a 3-day supply of a more expensive product is questioned, and it is better to wait and get the more economical product to the patient.

4. After the pharmacist explains to the patient that PA approval is required and that there is a good chance that the prescription will be changed, the patient may just decide to wait and get the medication later, after the physician has been called.

Obviously, there are some disadvantages or health risks when patients wait and do not start their medications on time. The patient's health may deteriorate and thus require additional medical attention such as added emergency department visits, physician visits, or hospitalizations. Thus, the decision to wait or not to provide the 72-hour emergency drug supply may have severe unintended consequences, which is why many respondents provided many examples of 72-hour emergency drug products that they would provide. These included inhalers, medications for nausea and vomiting, antiseizure medications, cough and cold medications, products to treat diabetes, and ear and eye drops.

Respondents also provided examples of 72-hour emergency drug products that they were reluctant to dispense. Examples 


\section{Examination of Why Some Community Pharmacists Do Not Provide 72-Hour Emergency Prescription Drugs to Medicaid Patients When Prior Authorization Is Not Available}

given were controlled substances, heavily abused medications, drugs packaged in containers where a 3-day supply is hindered, expensive medications, over-the-counter medications, and vitamins.

Another factor mentioned as to why respondents do not provide 72-hour drug supplies was that many will not dispense a 72-hour drug supply for prescriptions written by emergency room physicians. The problem with emergency room physicians is that they are very difficult to reach, it may take multiple telephone calls, and many times it takes several days to get the physician to return the telephone call if they eventually do return the call. Finally, it was mentioned that some physicians refuse to do PA requests, and many are not familiar with the PA process.

The results show that there are some legitimate reasons why 72-hour emergency drug supplies are not provided. The results also show that pharmacists are not the sole source of the problem of lack of adherence to the 72-hour emergency prescription requirement. Prescribers are "partners" in the problem and, in fact, in many cases, physicians precipitate the problem. In the researcher's opinion and based on the comments obtained from the questionnaires, it appears that many pharmacists are just tired of dealing with unreachable or uncooperative physicians, especially emergency room physicians. Educational efforts must reach out to this physician community.

\section{Limitations}

This study has limitations that may affect the generalizability of the results. The results should not be generalized nationally or to all Texas pharmacies/pharmacists/technicians because the sampling methodology employed only sampled those pharmacies that were identified by the Texas VDP as having a below-average number of PA prescriptions. Despite multiple mailings and follow-up phone calls, nonresponse bias is still a threat. Furthermore, the methodology asked the pharmacistin-charge/manager to distribute the questionnaires to a staff pharmacist and a pharmacy technician. The pharmacist-incharge was to complete the third questionnaire. How the pharmacist and technician were selected is unknown. This was most likely a convenience sample and not a random selection. That is, whoever was on duty at the time the questionnaires were being distributed probably received the questionnaire. Another possibility is that the pharmacist-in-charge selected people who he/she thought were the "most knowledgeable" or perhaps "the more favorable" or who could provide the "best" response. Finally, although questionnaire items were pretested and the items were reviewed many times by various people, respondents may not have interpreted the item(s) or question(s) as intended by the researcher or the VDP.

It is recognized that perceptions and opinions change or evolve over time. It is possible that the views expressed in this study may not be the same if the study were to be conducted today. It is also possible that in reading the instrument, respondents' knowledge, opinions, and views changed as they completed the questionnaire. So the results expressed may not have been their perceptions prior to completing the instrument.

\section{Conclusions}

The results show that the issue of not providing 72-hour emergency medication when PA is unavailable is multifaceted. The problem of the lack of awareness of the federal and state requirements regarding this law can and should be addressed through educational programming dedicated to community pharmacists, pharmacy technicians, physicians, and especially to emergency room physicians. The results show that there are some legitimate reasons why 72-hour emergency drug supplies are not dispensed. The issue of drug packaging, especially for expensive medications in unit-of-use packaging, was frequently cited. Clearly, as this study points out, writing a simple blanket law may sound good, but when it comes to its implementation, unintended consequences will arise.

\section{Author}

MARVIN D. SHEPHERD, PhD, is Director, Center of Pharmacoeconomic Studies, College of Pharmacy, University of Texas at Austin.

AUTHOR CORRESPONDENCE: Marvin D. Shepherd, PhD, Director, Center of Pharmacoeconomic Studies, College of Pharmacy, University of Texas at Austin, Austin, TX 78712. Tel.: 512.471.5607;

Fax: 512.471.8762; E-mail: marvshepherd@austin.utexas.edu.

\section{DISCLOSURES}

Funding for this contract research was provided by the Texas Medicaid Vendor Drug Program of the Texas Health and Human Services Commission. The funding was provided directly to the University of Texas through the Office of Sponsored Research. No travel, consulting, or writing fees were paid.

\section{ACKNOWLEDGMENTS}

The author would like to thank the staff at the Texas Medicaid Vendor Drug program, especially Maribel Castoreno, for providing valuable comments and input on questionnaire items. The author also wants to acknowledge the staff at the Office of Survey Research at the University of Texas for distributing the questionnaires and collecting the data.

\section{REFERENCES}

1. The Public Health and Welfare Act, 42 USC, Chapter 7, Subchapter XIX, \$1396r-8(d)(5), (July 1, 1991).

2. Texas Medicaid Provider Procedures Manual: Medicaid Managed Care Handbook. Vol 2. August 2012: 9. Available at: http://www.tmhp. com/HTMLmanuals/TMPPM/2012/Vol2_Medicaid_Managed_Care_ Handbook.30.07.html. Accessed April 2, 2013. 
3. MacKinnon N, Kumar R. Prior authorization programs: critical review of the literature. J Manag Care Pharm. 2001;(7)4:297-302. Available at: http:// www.amcp.org/WorkArea/DownloadAsset.aspx?id=6422.

4. Elan L. Patient Safety Forum: Do state Medicaid preferred drug lists affect patient safety? Psychiatr Serv. 2005;56(8):1012-13.

5. Maier K. How implementing a prescription drug prior authorization program can decrease Medicare spending. Health Law Policy Brief. 2011;36:36-40.

6. Gencarelli, D. Medicaid prescription drug coverage: state efforts to control costs. National Health Policy Forum Issue Brief. 2003:790. Available at: http://w.nhpf.org/library/issue-briefs/IB790_StateRx_5-10-03.pdf. Accessed April 2, 2013
7. Adams A, Zhang F, LeCates R, et al. Prior authorization for antidepressants in Medicaid: effects among disabled dual enrollees. Arch Intern Med. 2009;169(8):750-56.

8. The Kaiser Commission on Medicaid and the Uninsured. The Medicaid drug benefit: highlights from the KCMU survey of states, 2003. Available at: http://www.npcnow.org/App_Themes/Public/pdf/Issues/pub_related_ research/pub_component/State\%20Medicaid\%20Program\%20Issues $\% 20$ Preferred\%20Drug\%20Lists\%202003.pdf. Accessed April 4, 2013.

9. Bergman D, Kaye N, Hoadley J, Crowley J. State design and use of prior authorization processes. National Academy for State Health Policy. Issue Brief 1. March 2006. Available at: http://www.onceinaweil.org/sites/default/ files/medicaid_pa_pdl.pdf. Accessed April 2, 2013. 


\section{APPENDIX A Opinions and Knowledge of the Texas Medicaid/CHIP Vendor Drug Program}

\section{2-Hour Emergency Prescription Questionnaire}

The Texas Medicaid/CHIP Vendor Drug Program (VDP) wants to know your opinion and understanding of the Dispensing 72-Hour Emergency Prescriptions to Medicaid recipients policy and procedures. Please answer the following questions and items and return the questionnaire in the provided addressed envelope. Your cooperation is appreciated. Thanks.

1. In the last month, please estimate how often you made the decision about providing a 72-hour emergency prescription for Medicaid recipients?
A. Less than 6 times last month
B. 6 to 10 times last month
C. 11 to 20 times last month
D. More than 20 times last month

2. In your opinion, is dispensing a 72-hour emergency prescription supply to a Medicaid recipient a problem?
A. No
B. Yes

2a. If yes, to what extent is it a problem?
A. A slight problem (problem rarely occurs)
B. A moderate problem (problem occurs once or twice a month
C. A serious problem (problems are common (weekly or more often)

3. Do you recall receiving educational materials, (brochures, postcards, faxes or online materials) in the last six months about the Texas Medicaid 72-hour emergency prescription program and procedures?
A. Yes
B. No-Please proceed to question 4
C. Can't remember-Please proceed to question 4

3a. If Yes, how did you receive the information?
A. Texas Vendor Drug program website
B. Letter sent directly to the pharmacy
C. Information distributed by the pharmacist-in-charge
D. E-mail message from Texas Vendor Drug Program
E. Message from the claims processor, after submitting a claim
F. Information from the RxUpdate newsletter
G. Other, please specify:

3b. Using the following scale, how would you rate the Texas educational materials about the 72-hour emergency prescription drug program?
A. Excellent
B. Very good
C._ Average
D. Poor
E. Do not recall

3c. If "average" or "poor," do you have any suggestions on how the educational efforts can be improved?

4. Are you aware that federal and Texas law requires that a 72-hour emergency supply of a prescribed drug be provided to Medicaid patients when prior authorization is not available?
A. Yes
B. No

5. Using the following scale, in general, how knowledgeable are the pharmacists you work with about the Texas Medicaid 72-hour emergency prescription policy and procedures?
A. Knowledgeable
B. Somewhat knowledgeable
C.__ Not very knowledgeable 


\section{APPENDIX A Opinions and Knowledge of the Texas Medicaid/CHIP Vendor Drug Program (continued)}

6. Using the following scale, in general, how knowledgeable are the pharmacy technicians you work with about the Texas Medicaid 72 -hour emergency prescription policy and procedures?
A._ Very knowledgeable
B._Somewhat knowledgeable
C._ Not very knowledgeable

7. At your pharmacy, in the last 30 days, please estimate how often you have seen the 72-hour emergency prescription NOT being used for Texas Medicaid recipients when prior authorization was not available?
A._ Never
B._ Once or twice a month
C._ Once a week
D._ Two to five times a week
E._Greater than five times a week

8. In your opinion, does the type of drug influence the decision on whether or not a 72-hour emergency supply will be dispensed?

A. $\quad$ Yes

8a. If yes, please give examples of drug products:

9. Are there any pharmacy internal or corporate business practices or rules used that may impede your pharmacy from dispensing 72-hour emergency prescriptions for Medicaid recipients?

A._ Yes

9a. If yes, please explain:

10. Please estimate the number of times in the last month you have seen when the drug product dispensed for the 72-hour emergency supply for Medicaid recipients was changed to a different product after prior authorization was obtained.

Number of times per month the drug product changed:

11. Using the following 5-point significance/importance rating scale, please write the number indicating the significance/importance rating in the space provided for each of the possible reasons/factors as to why 72-hour emergency prescriptions are not being dispensed to eligible Medicaid beneficiaries in your pharmacy?

1. Very high significance/very high importance factor

2. Moderate significance/moderate importance factor

3. Low significance/low importance factor

4. Very little significance/very little importance factor

5. No significance/not an important factor

A._In the pharmacist's professional opinion, the prescribed drug product was not essential (i.e., cough and cold product).

B._The pharmacist believes the prescription will most likely be changed with the prior authorization call, so why dispense a 72-hour supply of the originally prescribed drug.

C._ The pharmacist is reluctant to open a new "unit-of-use" container (especially 30-day supply bottle) and render the product size unusable for future patients.

D._Pharmacists or technicians do not fully understand the legal or processing procedures of a 72-hour emergency supply claim.

E.___ Dispensing a 72-hour emergency supply takes too much time.

F. The patient decided to wait to have the prescription filled at a later time.

G. Dispensing a 72-hour emergency supply is not encouraged by pharmacy or corporate management.

H._ Texas Medicaid prior authorization processes and 72-hour emergency supply procedures are confusing when compared to other third-party pay plans.

I. Other, please describe: 
Examination of Why Some Community Pharmacists Do Not Provide 72-Hour Emergency

Prescription Drugs to Medicaid Patients When Prior Authorization Is Not Available

APPENDIX A Opinions and Knowledge of the Texas Medicaid/CHIP Vendor Drug Program (continued)

Demographic Information

1. Which of the following best describes your pharmacy practice work environment?

A._Independent community pharmacy

B._Chain store pharmacy (five or more stores)

C._ Other, please describe:

2. From the following choices, mark the one that best depicts your position at the pharmacy where you are employed.
A._ Pharmacist-in-charge
B._Staff pharmacist
C._ Pharmacy owner
D._Lead pharmacy technician
E._ Staff pharmacy technician
F. Other, please specify:

3. How long have you been employed at this pharmacy? years and months

4. How long have you been practicing pharmacy or working as a pharmacy technician? years

Thanks for completing the questionnaire. Your input is very valuable to us. We are very appreciative. 
Examination of Why Some Community Pharmacists Do Not Provide 72-Hour Emergency

Prescription Drugs to Medicaid Patients When Prior Authorization Is Not Available

\section{APPENDIX B Flowchart of Sample}

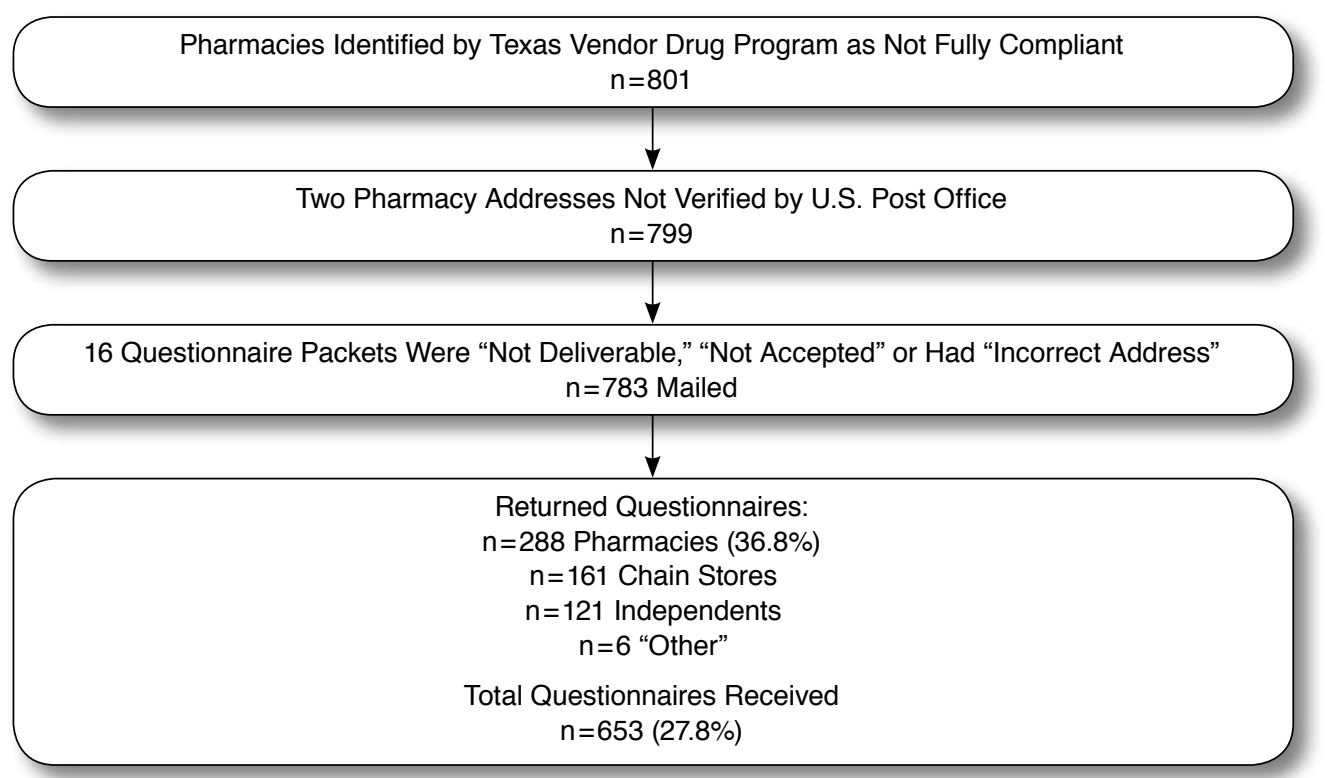

\section{APPENDIX C The Number and Percentage} of Respondents Who Were Aware or Unaware that the Law Requires a 72-Hour Emergency Prescription to Be Dispensed, Controlling for Practice Setting and Pharmacy Position

\begin{tabular}{|c|c|c|c|c|}
\hline \multirow{2}{*}{\multicolumn{2}{|c|}{$\begin{array}{l}\text { Pharmacy Position } \\
\text { "Awareness" Response }\end{array}$}} & \multicolumn{3}{|c|}{ Practice Setting } \\
\hline & & $\begin{array}{c}\text { All } \\
\text { Respondents } \\
\text { N (\%) }\end{array}$ & $\begin{array}{c}\text { Independent } \\
\text { n (\%) }\end{array}$ & $\begin{array}{l}\text { Chain } \\
\text { n (\%) }\end{array}$ \\
\hline \multirow{3}{*}{$\begin{array}{l}\text { Pharmacist-in- } \\
\text { charge/owners }\end{array}$} & Yes & $\begin{array}{ll}199 \quad(79.6) \\
\end{array}$ & $\begin{array}{ll}91 & (85.0) \\
\end{array}$ & $108 \quad(75.5)$ \\
\hline & No & $51 \quad(20.4)$ & $16 \quad(15.0)$ & $35 \quad(24.5)$ \\
\hline & Total $^{\mathrm{a}}$ & $250 \quad(100.0)$ & $107(100.0)$ & $143(100.0)$ \\
\hline \multirow{3}{*}{$\begin{array}{l}\text { Staff } \\
\text { pharmacists }\end{array}$} & Yes & $117 \quad(74.1)$ & $\begin{array}{ll}51 & (87.9) \\
\end{array}$ & $\begin{array}{ll}66 & (66.0) \\
\end{array}$ \\
\hline & No & $41 \quad(25.9)$ & $\begin{array}{ll}7 & (12.1) \\
\end{array}$ & $34 \quad(34.0)$ \\
\hline & Total $^{b}$ & $158(100.0)$ & $58 \quad(100.0)$ & $100 \quad(100.0)$ \\
\hline \multirow[t]{3}{*}{ Technicians } & Yes & $169 \quad(81.3)$ & $\begin{array}{ll}85 & (85.9) \\
\end{array}$ & $84 \quad(77.1)$ \\
\hline & No & $39 \quad(18.8)$ & $14 \quad(14.1)$ & $25 \quad(22.9)$ \\
\hline & Totalc & $208(100.0)$ & $99 \quad(100.0)$ & $109(100.0)$ \\
\hline \multirow[t]{3}{*}{ Total } & Yes & $485 \quad(78.7)$ & $227 \quad(86.0)$ & $258 \quad(73.3)$ \\
\hline & No & $131 \quad(21.3)$ & $37 \quad(14.0)$ & $94 \quad(26.7)$ \\
\hline & Total & $616 \quad(100.0)$ & $264 \quad(100.0)$ & $352(100.0)$ \\
\hline
\end{tabular}

aThere was no statically significant difference in the proportion of respondents who are aware of the 72-hour emergency prescription for pharmacists-incharge $\left(\chi^{2}=3.418 ; P=0.065\right)$.

${ }^{b}$ There was a statistically significant difference in the proportion of respondents who are aware of the law requiring a 72-hour emergency prescription for staff level pharmacists $\left(\chi^{2}=9.188 ; P=0.002\right)$.

cThere was no statically significant difference in the proportion of respondents who are aware of the 72-hour emergency prescription for pharmacists-in-charge $\left(\chi^{2}=2.634 ; P=0.105\right)$.

\section{APPENDIX D The Number and Percentage} of Respondents Who Were Aware or Unaware that the Law Requires a 72-Hour Emergency Prescription to Be Dispensed, by Length of Time in Pharmacy Practice

\begin{tabular}{|c|c|c|c|c|c|}
\hline \multirow{3}{*}{$\begin{array}{l}\text { Length of Time } \\
\text { in Pharmacy } \\
\text { Practice (Years) } \\
0-5 \\
\end{array}$} & \multicolumn{5}{|c|}{ Number and Percentage of Respondents } \\
\hline & $\begin{array}{l}\text { All Respondents } \\
\text { N (\%) }\end{array}$ & \multicolumn{2}{|c|}{$\begin{array}{l}\text { Aware } \\
\text { n (\%) }\end{array}$} & \multicolumn{2}{|c|}{$\begin{array}{c}\text { Unaware } \\
\text { n (\%) }\end{array}$} \\
\hline & $139 \quad(100.0)$ & 109 & $(78.4)$ & 30 & $(21.6)$ \\
\hline $6-10$ & $127 \quad(100.0)$ & 96 & $(75.6)$ & 31 & $(24.4)$ \\
\hline $11-15$ & $94 \quad(100.0)$ & 75 & $(79.8)$ & 19 & $(20.2)$ \\
\hline $16-29$ & $137 \quad(100.0)$ & 112 & $(81.8)$ & 25 & $(18.2)$ \\
\hline 30 or more & $(100.0)$ & 101 & $(78.9)$ & 27 & $(21.1)$ \\
\hline All employees & $(100.0)$ & 493 & $(78.9)$ & 132 & $(21.1)$ \\
\hline
\end{tabular}

a 28 respondents did not provide the length of time they have been in pharmacy practice or answer this question.

${ }^{b}$ There was no statistically significant difference among the respondents in how many were aware of the law requiring a 72-hour emergency prescription $\left(\chi^{2}=1.567 ; P=0.815\right)$. 
Examination of Why Some Community Pharmacists Do Not Provide 72-Hour Emergency

Prescription Drugs to Medicaid Patients When Prior Authorization Is Not Available

APPENDIX E Frequencies of the Categorized Responses of Comments and Product Examples from Respondents Who Indicated "Yes" to the Type of Product that Influences Their Decision on Whether or Not to Dispense a 72-Hour Emergency Prescription, Controlling for Pharmacy Position

\begin{tabular}{|c|c|c|c|c|}
\hline Category & \begin{tabular}{|c|} 
All \\
Respondents \\
$\mathrm{N}(\%)$ \\
\end{tabular} & $\begin{array}{c}\text { Pharmacist- } \\
\text { in-Charge } \\
n(\%)\end{array}$ & $\begin{array}{c}\text { Staff } \\
\text { Pharmacists } \\
\text { n (\%) }\end{array}$ & $\begin{array}{c}\text { Pharmacy } \\
\text { Technician } \\
\text { n (\%) }\end{array}$ \\
\hline $\begin{array}{l}\text { Controlled } \\
\text { substances }\end{array}$ & $\begin{array}{|ll|}92 & (21.6) \\
\end{array}$ & $38(22.6)$ & $\begin{array}{|ll|}21 & (18.8) \\
\end{array}$ & $33(22.8)$ \\
\hline $\begin{array}{l}\text { Antibiotic/anti- } \\
\text { infective }\end{array}$ & $46 \quad(10.8)$ & $17 \quad(10.1)$ & $10 \quad(8.9)$ & 19 (13.1) \\
\hline $\begin{array}{l}\text { Packaging presents } \\
\text { difficulty }\end{array}$ & $45 \quad(10.6)$ & $21 \quad(12.5)$ & $11 \quad(9.8)$ & $13 \quad(9.0)$ \\
\hline Inhalers & $38 \quad(8.9)$ & $18 \quad(10.7)$ & $(7.1)$ & $12 \quad(8.35)$ \\
\hline $\begin{array}{l}\text { Expensive/high } \\
\text { price }\end{array}$ & $30 \quad(7.1)$ & $11 \quad(6.5)$ & $10 \quad(8.9)$ & $9 \quad(6.2)$ \\
\hline Cough/cold agents & $(6.3)$ & $(5.4)$ & $(6.3)$ & $(8.3)$ \\
\hline $\begin{array}{l}\text { Nausea/vomiting/ } \\
\text { Zofran }\end{array}$ & $22 \quad(5.2)$ & $(5.4)$ & $(7.1)$ & (3.4) \\
\hline Diabetes/insulin & $(2.4)$ & $(3.0)$ & $(2.7)$ & $(1.4)$ \\
\hline Eye or ear drops & $(2.4)$ & $(1.8)$ & $(2.7)$ & $(2.8)$ \\
\hline $\begin{array}{l}\text { Antiseizure } \\
\text { products }\end{array}$ & (1.4) & $(1.2)$ & $(1.8)$ & (1.4) \\
\hline $\begin{array}{l}\text { Blood pressure } \\
\text { products }\end{array}$ & $6 \quad(1.4)$ & $3 \quad(1.8)$ & $2 \quad(1.8)$ & $(0.7)$ \\
\hline Pain & $(0.9)$ & $(1.8)$ & $(0.0)$ & $(0.7)$ \\
\hline Emergency use & $(0.5)$ & $(0.0)$ & $(0.9)$ & $(0.7)$ \\
\hline Heart/cardiac & $2 \quad(0.5)$ & $1 \quad(0.6)$ & $0 \quad(0.0)$ & $1 \quad(0.7)$ \\
\hline Other & $84 \quad(19.8)$ & $28 \quad(16.1)$ & $26 \quad(23.2)$ & $30 \quad(20.7)$ \\
\hline Total ${ }^{\mathrm{a}}$ & $425(100.0)$ & $168(100.0)$ & $112(100.0)$ & $145(100.0)$ \\
\hline
\end{tabular}

\section{APPENDIX F The Mean Number of Times that} Drug Products Dispensed in the Last Month for 72-Hour Emergency Prescriptions Were Changed after Obtaining Prior Authorization, by Pharmacy Type and Position Level

\begin{tabular}{|c|c|c|}
\hline \multicolumn{2}{|l|}{ Category } & $\begin{array}{c}\text { Mean } \\
\text { (SD) } \\
\mathbf{n}\end{array}$ \\
\hline \multirow[t]{3}{*}{ Pharmacy type } & Independent pharmacies & $\begin{array}{c}3.17 \\
(5.92) \\
247\end{array}$ \\
\hline & Chain store pharmacies & $\begin{array}{c}2.99 \\
(7.63) \\
319\end{array}$ \\
\hline & Totala,b & $\begin{array}{c}3.04 \\
(6.87) \\
566 \\
\end{array}$ \\
\hline \multirow[t]{4}{*}{ Position } & Pharmacists-in-charge & $\begin{array}{c}3.55 \\
(8.94) \\
234\end{array}$ \\
\hline & Staff pharmacists & $\begin{array}{c}3.20 \\
(6.37) \\
146 \\
\end{array}$ \\
\hline & Technicians & $\begin{array}{c}2.31 \\
(3.59) \\
198\end{array}$ \\
\hline & Totala,c & $\begin{array}{c}3.04 \\
(6.87) \\
578\end{array}$ \\
\hline
\end{tabular}

a75 respondents did not answer this question with a numerical value.

${ }^{b}$ There was no statistically significant difference among the different store types in how often the drug product was changed after obtaining prior authorization ( $F=0.384 ; P=0.681)$

cThere was no statistically significant difference among the different positions in how often the drug product was changed after obtaining prior authorization $(F=1.802 ; P=0.166)$ 


\section{TABLE 5 APPENDIX A Sampling of Other Reasons/Factors}

for Not Dispensing 72-Hour Emergency Prescriptions

- They are for high-cost meds that have other alternatives to them.

- Some physicians will not do PA, especially ER doctors.

- Laziness. Extra work because Rx has to be entered again for PA to remain in system and be faxed to doctor.

- We have no way to submit a 72-hour supply for reimbursement.

- MDs usually take longer than 72 hours to do PA, so why have patient start med when more than likely it won't be completed in 72 hours.

- Educational material is necessary in order to promote the use of emergency supplies by all personnel especially RPhs (many are not aware of the codes).

- It's hard to dispense 72 hours of antibiotics that have to be mixed because they are stock size. Ointment cream because of size. Eye drops, inhalers, insulin. These drugs are different, but we would and do see that patient is taken care of.

- Drug reps often detail physicians' Texas PA drugs, and the physicians think those detailed drugs are covered.

- Drug reps are often confused or are misinformed about what drugs are covered.

- Oversight. Working too fast and not realizing it is a PA for Medicaid, and we could and should use the override.

- Medicine is prescribed by doctors who "don’t do prior auths." Prime example is local emergency room docs.

- Prior authorization codes do not work and Medicaid is not available. This is the \#1 problem.

- Very few prescriptions classify as an "emergency."

- Pharmacy employees do not know when use of the 72-hour emergency supply is appropriate.

- Fear of being audited for a 3-day supply, and prescriber did not complete PA.

- Chargeback and ER doctors do not do PA. TXMED formulary may change, but website not updated.

- We are not assured of getting paid. Many of our prescriptions are from ER doctors, and those doctors simply will NOT do a prior authorization.

- A 72-hour dose is not enough over a weekend. If it occurs on Friday, then the patient is out by Sunday; the doctor is closed all weekend, and they are not working on it.

- Most prescriptions are from hospitals that do not do prior authorization so therefore the prescription must be changed.

- Stock bottles or medication that cannot be broken to a 3-day supply, i.e., an inhaler that would normally last 30 days. Pharmacist is afraid we won't get reimbursed for the full price of the medication.

- We have seen a rise in prior auth. scripts. During business hours, we contact the doctor to submit the prior auth. The patient leaves the pharmacy hoping the prior auth. will be done. Some doctors are taking several days to take care of the issue even though some medications are written by ER physicians or are only for 72-hour supplies to begin with.

- The dosage is higher than the usual dose for the age and weight of the patient. Medicine is contraindicated.

- Time and costs involved plus keeping track of dispensed Rxs.

- 99 percent of physicians do not call for prior authorization ... an exorbitant number of prior authorizations are sent back to physician.

- Doctors and their nurses frequently refuse to complete prior auths. and change the drug before the patient comes in to pick up their filled Rx.

- CII Rx.

- The medication rejection does not tell you that either an emergency override is possible or give you the steps needed to complete in the rejection. If the knowledge of the process is not already known, then this can cause nonprocessing.

- Doctors do not know how the 72-hour supply works/is available. Medicaid has brand name on formulary when generic would be much more easy to use.

- If prior auth. takes longer than 72 hours, the patient expects the whole prescription whether approved or not. Uneven number of pills left on Rx; example: Rx for $\# 30$ of $X$, we give \#3, there are $27+2$ refills left. At next fill, do we only fill 27 ? No, we fill 30 and Rx is left short at the end, which confuses/annoys patients. 